\title{
Factors determining the aggregation of urinary mucoprotein
}

\author{
E. G. McQUEEN AND G. B. ENGEL \\ From the Department of Pharmacology and Pharmacy of the University of Otago and \\ the Wellcome Medical Research Institute, Dunedin, New Zealand
}

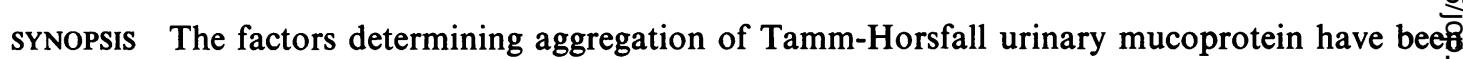
examined using the technique of light-scattering photometry, which has allowed the study to bs performed at the concentrations of the mucoprotein in which it occurs in the urine in vivo.

The tendency to formation of aggregates is enhanced by increases in concentration of the mucoprotein, by increases in electrolyte concentration within physiological limits, and by lowering of the $p \mathrm{H}$ within the physiological range. The effects of $1: 2$ and 2:1 electrolytes are somewhat different from those of $1: 1$ electrolytes. The data suggest that the isoelectric point of Tamm-Horsfay protein is higher than previously thought.

Neither the physiological significance nor the pathogenetic potentiality of the urinary mucoprotein described originally by Tamm and Horsfall (1950) have as yet been evaluated. It has been suggested that it is a phylogenetic relic of an avian or reptilian ancestor faced with the necessity of extruding a solid excretory product from the renal tract (Longley, Burtner, and Monis, 1963). A protective action based on its rheological properties (Bettelheim, 1963) would be in conformity with the ubiquitous occurrence of mucus at epithelial surfaces. The viral inhibitory properties which led to its first characterization by microbiologists seem to be of little practical importance, and the protective effect does not appear to extend to bacteria (McKenzie and McQueen, unpublished observations).

However, the mucoprotein does appear to be the principal constituent of urinary casts (McQueen, 1962), and may thus well be of some importance in renal disease. Urinary mucoprotein may also be a factor in the pathogenesis of acute renal failure (Patel, McKenzie, and McQueen, 1964). The appearance of casts in the urine after strenuous exercise has been shown to correlate well with the concentration of Tamm-Horsfall mucoprotein (Patel, 1964), suggesting that casts are formed from the mucoprotein when it becomes sufficiently concentrated in the renal tubules to agglutinate into formed masses.

Tamm and Horsfall (1950) utilized the propensity of inorganic ions for producing aggregation of the mucoprotein to precipitate the material from urine.

Received for publication 23 October 1965.
They found that it could be isolated from urine almost quantitatively by adding sodium chloride to 0.58 molar concentration. The extensive study Curtain (1953) showed additionally that $\mathrm{pH}$ affected solubility. Decrease in $p \mathrm{H}$ was associated with decreased solubility (and increased viscosity) at given ionic strength. However, the Tamm-Horsfal mucoprotein concentrations employed in his study were well above those ever likely to be attained vivo.

It was, therefore, decided to perform some studies on the conditions under which aggregation of Tamn? Horsfall mucoprotein occurs in physiological con centration using the technique of light-scattering photometry (cf. Maxfield, 1959).

\section{METHODS}

A Brice-Phoenix light-scattering photometer (mode 2000D) was used. This is a dual photomultiplier photo? meter and was arranged so that one photometer tube received light scattered at an angle of $45^{\circ}$ from the incis dent beam (of wavelength $546 \mathrm{~m} \mu$ ). The other phot $\sigma^{\circ}$ meter tube received directly transmitted light. A corf bination of filters enabled satisfactory readings to obtained by suitable adjustment of the photomultiplifi gain controls. Readings were recorded on a Sargeft model GRL pen recorder using a logarithmic scale.

Tamm-Horsfall mucoprotein was prepared frō normal urine by precipitation with sodium chloride at concentration of 0.58 molar. The precipitate was dif solved in distilled water and centrifuged at 1,750 r.p. for 30 minutes to remove any formed elements. This precess was repeated twice. The final solution was dialyserd 
in the cold against a large volume of distilled water until no further chloride ions could be demonstrated in the solution. The Tamm-Horsfall mucoprotein was then concentrated by negative-pressure dialysis, and its concentration measured by dry-weight estimation. Dry weight (per unit weight of solution) was estimated by drying in vacuo over phosphorus pentoxide until a constant weight was achieved.

Tamm-Horsfall mucoprotein in a range of concentration of from 0.01 to $0.08 \mathrm{mg} . / \mathrm{ml}$. in either a Sorensen's phosphate or in some instances a Walpole's acetate buffer of appropriate $p \mathrm{H}$ (Documenta Geigy, 1962) was placed in a semi-octagonal cell in the light path and agitated by a magnetic stirrer. Tamm-Horsfall mucoprotein tended to aggregate at the lower $p \mathrm{H}$ levels without addition of further ions when buffer solutions of the usual strengths (M/15 in the case of Sorensen's, and $M / 5$ for Walpole's) were used. These were therefore further diluted to a concentration of $M / 75$ in the case of Sorensen's phosphate buffer and $M / 25$ in the case of Walpole's acetate buffer.

Baseline records of scattered light at $45^{\circ}$ and of transmitted light were obtained. A $2 \cdot 5$ molar solution of $\mathrm{NaCl}$ (or other electrolyte of suitable ionic strength) in corresponding buffer was then injected into the cell at a rate, which was constant for the experiment, of between 0.25 and $0.30 \mathrm{ml} . / \mathrm{min}$. This was achieved by passing a thin polythene tube through a small hole in the photometer casing from a pump outside.

A relatively sudden and progressive increase in intensity of scattered light indicated the commencement of aggregation of Tamm-Horsfall mucoprotein. The ionic strength contributed by the electrolyte added to that point could be calculated from the flow rate and time elapsed and checked by weight. When the increase in light scattering had become fully developed the intensity of transmitted light could be seen to be diminished, but the effect on transmitted light was a much less sensitive index of aggregation. Increase in light scattering at $45^{\circ}$ could not be consistently observed at concentrations below $0.008 \mathrm{mg} . / \mathrm{ml}$.

\section{RESULTS}

EFFECT OF ADDITION of $\mathrm{NaCl}$ AND of $p \mathrm{H}$ This is shown in Fig. 1 for four solutions of approximately the same concentration of Tamm-Horsfall mucoprotein in buffer solutions which before dilution were $p \mathrm{H} 5,6,7$, and 8 . To these solutions 2.5 molar $\mathrm{NaCl}$ solution in the same buffer was added via the polythene tubing from the pump outside the photometer casing. Both the initial dilution and subsequent addi-

TABLE I

\begin{tabular}{ccc}
$\begin{array}{l}\text { pH before Dilution } \\
(\mathrm{M} / 15 \text { Buffer })\end{array}$ & $\begin{array}{l}\text { pH after Dilution } \\
(\mathrm{M} / 75 \text { Buffer })\end{array}$ & $\begin{array}{l}p \mathrm{H} \text { at Aggregation } \\
\text { Point }\end{array}$ \\
\hline 5.0 & $5 \cdot 4$ & $5 \cdot 2 \pm 0 \cdot 1$ \\
6.0 & $6 \cdot 2$ & $5.9 \pm 0 \cdot 1$ \\
7.0 & 7.2 & $6.9 \pm 0 \cdot 1$ \\
8.0 & 7.9 & $7.6 \pm 0.1$
\end{tabular}

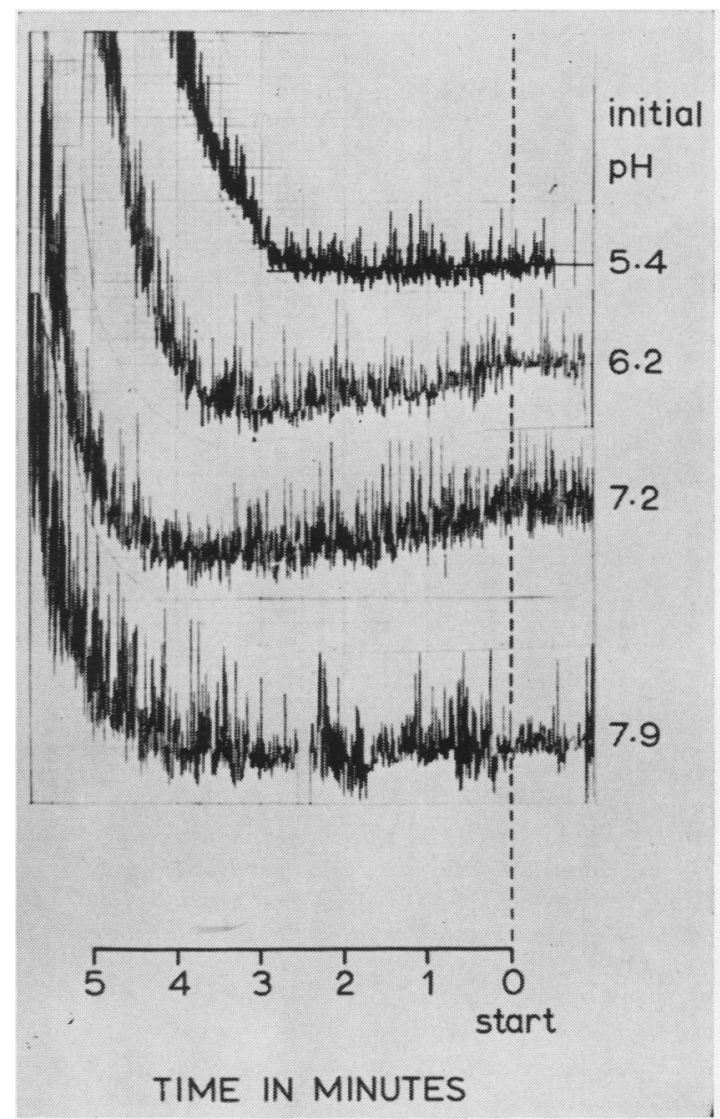

FIG. 1 Records of scattered light at $45^{\circ}$ for TammHorsfall mucoprotein solutions of approximately the same concentration at four pH levels (phosphate buffer). Addition of $2.5 \mathrm{M} \mathrm{NaCl}$ commenced at $\mathrm{O}$. Recordings move right to left.

tion of the relatively concentrated electrolyte solution modified the $\mathrm{pH}$ to a small extent. These effects are shown in Table $\mathbf{I}$.

It can be seen in Fig. 1 that there was a relatively sharp increase in light scattering indicating that Tamm-Horsfall mucoprotein aggregated after the addition of amounts of $\mathrm{NaCl}$ which were progressively less with decreasing $p \mathrm{H}$. The results obtained in this manner for a range of Tamm-Horsfall mucoprotein concentrations varying from 0.01 to 0.08 $\mathrm{mg} . / \mathrm{ml}$. are shown in Figure 2 . Lines of best fit have been drawn for each $\mathrm{pH}$ level. It can be seen that, as might be expected, aggregation occurred at progressively lower ionic strength with increasing concentration of mucoprotein. Similarly the lower the $p H$ within the range approximately $5-8$, i.e., the physiological range of urinary $p \mathrm{H}$, the lower the ionic strength necessary to produce aggregation. 


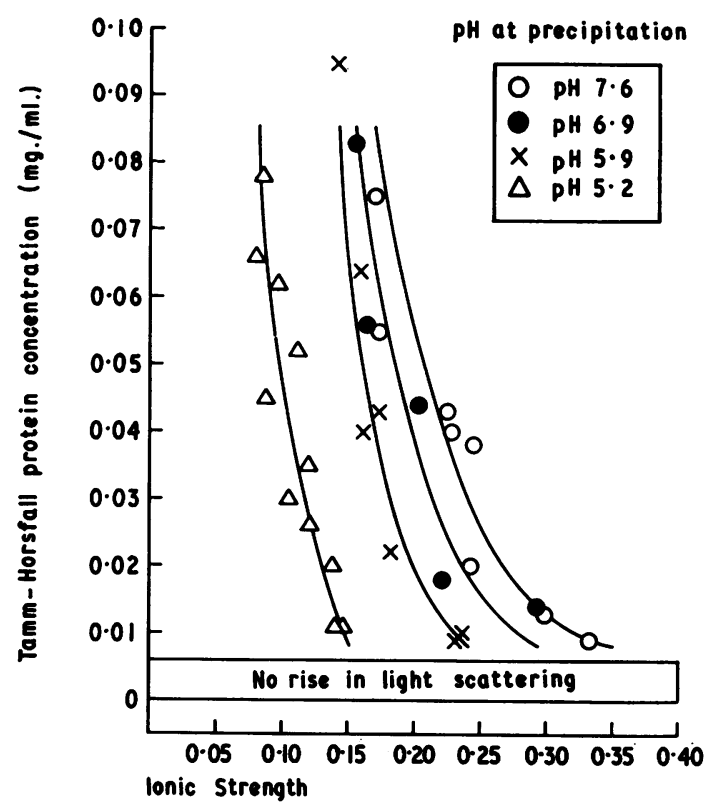

FIG. 2 Occurrence of aggregation in solutions of TammHorsfall mucoprotein of varying concentration $(\mathrm{mg} . / \mathrm{ml}$.) at four different $\mathrm{pH}$ levels (see Table 1), the concentration plotted against ionic strength contributed by buffer and added $\mathrm{NaCl}$.

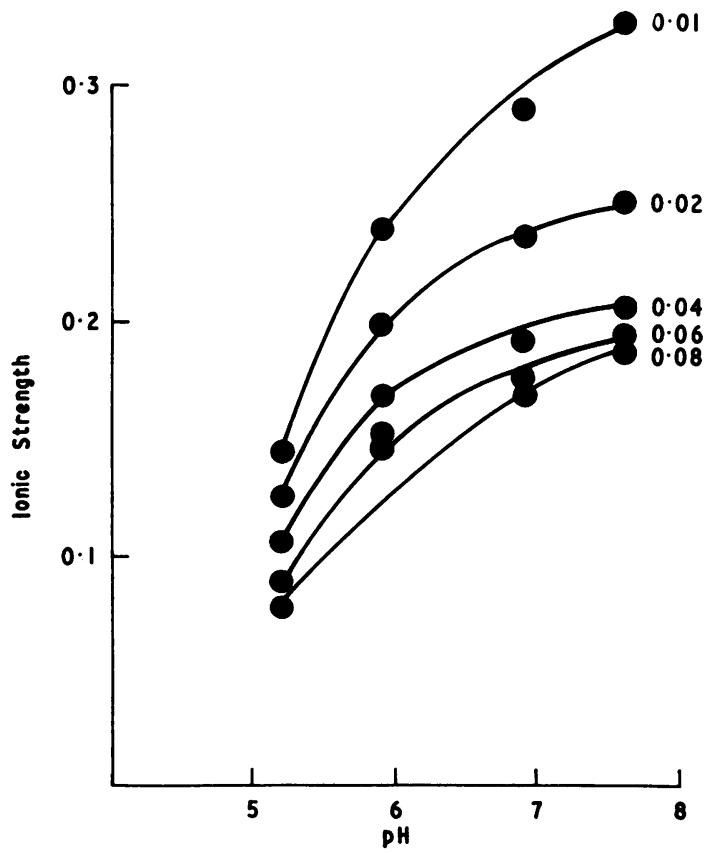

FIG. 3 Data from Fig. 2 replotted to show convergence of graphs towards isoelectric point.
The data from Fig. 2 have been plotted again in Figure 3. The curves in Fig. 3 appear to be con은 verging on a point of minimum solubility at about $p \mathrm{H} 4.8$ which would seem likely to be the isoelectric? point of the protein (Tanford, 1961).

The observations on the effects of $p \mathrm{H}$ were extended to a lower $p \mathrm{H}$ range by use of acetic acid $\stackrel{5}{-}$ acetate buffer $(M / 25)$. The effects of addition ob $2.5 \mathrm{M} \mathrm{NcCl}$ to urinary mucoprotein solutions of similar concentrations at initial $p \mathrm{H}$ levels $4.8,4 \cdot 4 \cdot \overrightarrow{0}$ $4 \cdot 2,4.0,3.8$, and 3.6 are shown in Figure 4. The rise in baseline occurred at progressively shorter inter $\vec{w}$

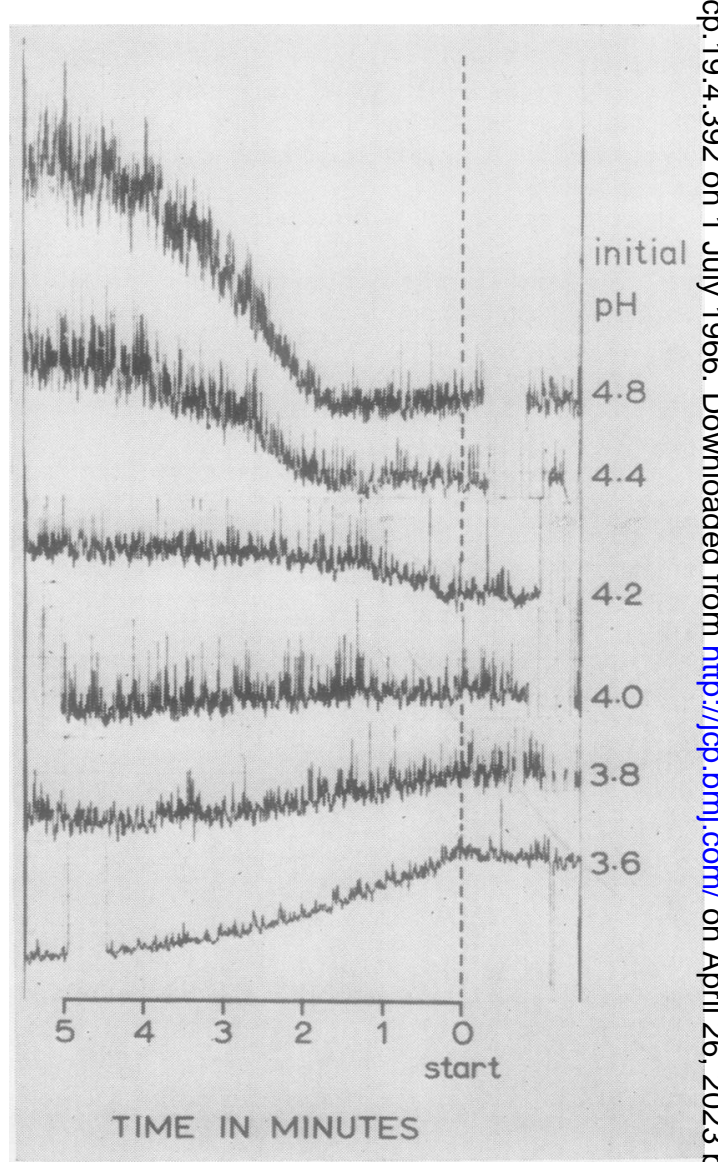

FIG. 4 Records as for Fig. 1 at lower pH range (acetate buffer).

vals. However, at the same time the degree of increase in light scattering concomitantly diminished witlo

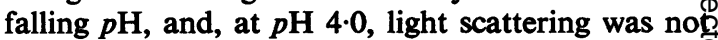
increased. Below pH 4.0 light scattering actuall 8 diminished with the addition of the $2.5 \mathrm{M} \mathrm{NacCl}$. IO would seem that at $p \mathrm{H}$ levels below 5.0, although 


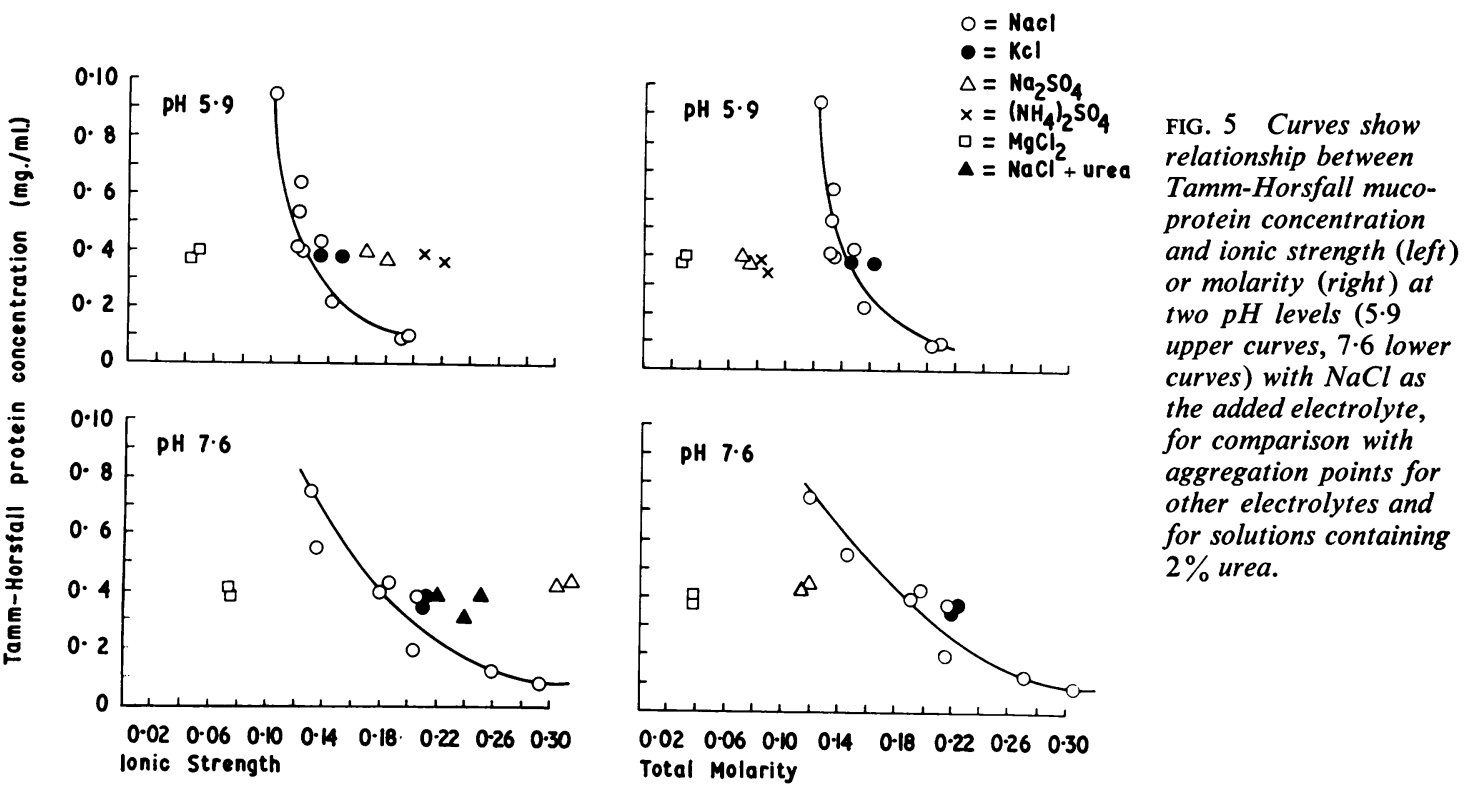

aggregation of Tamm-Horsfall mucoprotein occurs with the addition of smaller amounts of $\mathrm{NacCl}$, the solubility of the product progressively increases, and this is in conformity with the previous experiment, suggesting an isoelectric point at about $\mathbf{4 \cdot 8}$.

The effects of adding electrolytes other than $\mathrm{NaCl}$ and also urea are shown in Fig. 5 for two $p \mathrm{H}$ levels, 5.9 (upper) and 7.6 (lower), expressed in terms both of ionic strength (left) and molarity (right).

Substitution of $\mathrm{KCl}$ for $\mathrm{NaCl}$ as the added electrolyte led to aggregation of Tamm-Horsfall mucoprotein at electrolyte concentrations not significantly different from those which would have been anticipated with $\mathrm{NaCl}$. With 1:2 and 2:1 electrolytes, however, there was a considerable divergence from the curves for the 1:1 electrolytes in terms both of ionic strength and molarity. With $\mathrm{Na}_{2} \mathrm{SO}_{4}$ at $p \mathrm{H} 5.9$ and 7.6 and with $\left(\mathrm{NH}_{4}\right)_{2} \mathrm{SO}_{4}$ at 5.9 (the higher $p \mathrm{H}$ could not be attained without increasing buffer strength) aggregation occurred at a molar concentration somewhat less, and an ionic strength somewhat more, than with the 1:1 electrolytes. With the $1: 1$ electrolytes at $p \mathrm{H} 5.9$ aggregation plotted against activity (equation of Guntelberg, 1926) gives a straight line relationship. With $\mathrm{Na}_{2} \mathrm{SO}_{4}$ and $\left(\mathrm{NH}_{4}\right)_{2} \mathrm{SO}_{4}$, correspondence in terms of activity again was not close but it would seem that with these salts the findings are consistent with an activity relationship. The magnesium ion, however, seems to have a specific effect in causing aggregation at much lower concentrations.
Urea appeared to have no effect in promoting Tamm-Horsfall mucoprotein aggregation. In fact the tendency with addition of urea to the electrolyte under study was in the reverse direction. The effects of adding $2 \%$ urea to both the Tamm-Horsfall solution and added $\mathrm{NaCl}$ can be seen in Figure 5 (lower left). Aggregation occurred in each instance when the ionic strength (due to the added $\mathrm{NaCl}$ ) was slightly higher than in the absence of urea. Total molarity for the solutions with this concentration of urea is approximately 0.25 and is off the corresponding graph (lower right). The effect of adding mannitol was also found in other experiments to be insignificant.

The effect of the presence of human serum albumin on aggregation of Tamm-Horsfall mucoprotein was to stabilize the solution, and to retard somewhat the point at which aggregation occurred. The effect of the albumin itself in causing appreciable increase in baseline light scattering and also in modifying $p \mathrm{H}$ made it difficult to make precise comparison at high albumin concentrations. However, using an albumin concentration of $0 \cdot 10 \%$ satisfactory results could be obtained. The concentration of added $\mathrm{NaCl}$ at which the increase in light scattering occurred with and without albumin was estimated in $p \mathrm{H} \quad 7.9 \mathrm{M} / 75$ phosphate buffer solutions with virtually identical Tamm-Horsfall mucoprotein concentrations $(0.052 \pm 0.003 \mathrm{mg}$. $/ \mathrm{ml}$.). The concentration of $\mathrm{NaCl}$ at which aggregation commenced was $0.204 \mathrm{M}$ without and $0.265 \mathrm{M}$ with $0.10 \%$ albumin 
(average of two experiments each). The final $p \mathrm{H}$ of the solutions without albumin were 7.62 and with albumin $7 \cdot 52$.

\section{DISCUSSION}

The physical characteristics of Tamm-Horsfall mucoprotein have undergone extensive study both by the initial investigators (Tamm and Horsfall, 1952) and others (Curtain, 1953; Tamm, Bugher, and Horsfall, 1955; Porter and Tamm, 1955; Maxfield, $1959,1960,1961)$ and have now been clearly demonstrated (Maxfield and Davis, 1963). However, in most experiments directed towards this purpose, such as those detailed by Maxfield (1960), the tendency towards growth of aggregates constituted a source of experimental inconvenience, and the conditions leading to aggregate formation were specifically avoided.

The experiments of Curtain (1953) described the effects of $p \mathrm{H}$ and ionic strength on solutions of the mucoprotein, but the techniques employed, particularly viscosity measurements, required very much more concentrated solutions of Tamm-Horsfall mucoprotein, of the order of 10 to 100 -fold that normally encountered in urine. However, extrapolation of the present data can be envisaged as giving reasonable correspondence with his solubility curves.

The effects of electrolytes on viscosity and solubility were explained by Curtain on the basis of neutralization of electro-chemical repulsive forces allowing the forces of intermolecular attraction to operate. At the very much lower mucoprotein concentrations under study in the present experiments the production of aggregation by sodium chloride is clearly a function of ionic strength, and with the 2:1 electrolytes studies (sodium sulphate and ammonium sulphate) the effects would appear to be consistent with some expression of ionic activity. With magnesium chloride there seemed to be some specific effect of the $\mathrm{Mg}^{++}$ion in producing aggregation, and this was also observed by Curtain (1953).

The occurrence of aggregations at the extremely low concentrations of mucoprotein under study in the present experiments is attributable to the very large size of the long rod-like molecule. Maxfield (1961) has calculated that the volume necessary to permit the molecule (of length $1 \cdot 2 \mu$ in its natural form) to rotate freely in Brownian motion is such that the effects of molecular interaction are likely to become pronounced at mucoprotein concentrations slightly above those normally found in human urine.

The range of concentration of Tamm-Horsfall mucoprotein in the urine of normal subjects is approximately that covered by the present experio ments (see McKenzie, Patel, and McQueen, 1964) although in very concentrated urine it may b. somewhat higher.

The range of electrolyte concentration studied if the present experiments is approximately that ove which urinary electrolyte concentration may vary The recognized maximum chloride concentration is about 0.34 molar and the maximum total electrolyt $\varepsilon^{2}$ concentration is not much higher (Smith, 1951).

The extreme variation of $p \mathrm{H}$ in the urine is from 4.8 to 8.2 (Smith, 1951), the range again being approximately that covered by the experiments emes ploying the phosphate buffer. A by-product of the present experiments was an indication that the iso electric point of the mucoprotein is considerablit higher than the figure previously quoted (Tamm and Horsfall, 1950) of 3.5. It appears to be approximately 4.8 and thus to fall at the lower end of the physio logical range. The effect of acidification of the urine in preserving casts is well known. The possible importance of increasing urinary $p \mathrm{H}$ in conditions: in which formation of casts may have an actuallg deleterious effect has perhaps not been sufficiently considered.

We are indebted for financial assistance to the Medicad Research Council of New Zealand and to the Goldem Kiwi Medical Research Distribution Committee. We als\& wish to express our indebtedness to Mr. David Ingramo M.Sc., for his assistance with some of the experimentap work, and to Mrs. Eleanor Williamson for technica稆 assistance.

\section{REFERENCES}

Bettelheim, F. A. (1963). Ann. N.Y. Acad. Sci., 106, 247.

Curtain, C. C. (1953). Aust. J. exp. Biol. med. Sci., 31, 255.

Documenta Geigy (1962). Scientific Tables, 6th ed., edited by K Diem, pp. 314-315. Geigy Pharmaceutical Co., Manchester.

Guntelberg, E. (1926). Hoppe-Seylers Z. physiol. Chem., 123, 199.

Longley, J. B., Burtner, H. J., and Monis, B. (1963). Ann. N.Y. Acad Sci., 106, 493.

McKenzie, J. K., Patel, R., and McQueen, E. G. (1964). Aust. Ann? Med., 13, 32.

McQueen, E. G. (1962). J. clin. Path., 15, 367.

Maxfield, M. (1959). Arch. Biochem., 85, 382.

(1960). Ibid., 89, 281.

(1961). Biochim. biophys. Acta (Amst.). 49, 548.

and Davis, M. S. (1963). Ann. N.Y. Acad. Sci., 106, 288

Patel, R. (1964). Aust. Ann. Med., 13, 170.

McKenzie, J. K., and McQueen, E. G. (1964). Lancet, 1, 457

Porter, K. R., and Tamm, I. (1955). J. biol. Chem., 212, 135.

Smith, H. W. (1951). The Kidney: Structure and Function in Healt and Disease. Oxford University Press, New York.

Tamm, I., and Horsfall, F. L., Jr. (1950). Proc. Soc. exp. Biol. (N. Y. $74,108$.

,-- (1952). J. exp. Med., 95, 71.

Bugher, J. C., and Horsfall, F. L., Jr. (1955). J. biol. Chem 212, 125.

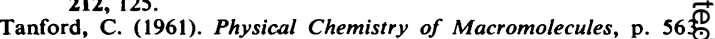
Wiley, New York. 